\title{
Biaxially Aligned Template Films Fabricated by Inclined-Substrate Deposition for YBCO-Coated Conductor Applications
}

\author{
Beihai Ma, Meiya Li, Rachel E. Koritala, Brandon L. Fisher, Alison R. Markowitz, \\ Robert A. Erck, Steve E. Dorris, Dean J. Miller, and U. (Balu) Balachandran
}

\begin{abstract}
Inclined substrate deposition (ISD) has the potential for rapid production of high-quality biaxially textured buffer layers, which are important for YBCO-coated conductor applications. We have grown biaxially textured MgO films by ISD at deposition rates of $20-100 \AA \AA / s e c$. Columnar grains with a roof-tile surface structure were observed in the ISD-MgO films. X-ray pole figure analysis revealed that the (002) planes of the ISD-MgO films are tilted at an angle from the substrate normal. A small $\phi$-scan full-width at half maximum (FWHM) of $\approx 9^{\circ}$ was observed on $\mathrm{MgO}$ films deposited at an inclination angle of $55^{\circ}$. In-plane texture in the ISD MgO films developed in the first $0.5 \mu \mathrm{m}$ from the interface, then stabilized with further increases in film thickness. YBCO films deposited by pulsed laser deposition on ISD-MgObuffered Hastelloy $\mathrm{C} 276$ substrates were biaxially aligned with the c-axis parallel to the substrate normal. $T_{c}$ of $91 \mathrm{~K}$ with a sharp transition and transport $J_{c}$ of $5.5 \times 10^{5} \mathrm{~A} / \mathrm{cm}^{2}$ at $77 \mathrm{~K}$ in self-field were measured on a YBCO film that was $0.46-\mu \mathrm{m}$ thick, 4-mm wide, 10-mm long.
\end{abstract}

Index Terms-YBCO thin film, Coated conductor, Inclined substrate deposition, Biaxial texture

\section{INTRODUCTION}

2 ND generation coated conductors and superconducting wires are promising for high-current-carrying applications and other electric power devices operating at temperatures that approach liquid nitrogen [1-3]. Textured template films or buffer layers are needed for deposition of biaxially aligned $\mathrm{YBa}_{2} \mathrm{Cu}_{3} \mathrm{O}_{7-\delta}$ (YBCO) films to overcome weak links and, therefore, to achieve high critical current density $\left(\mathrm{J}_{\mathrm{c}}\right)$ in the

Manuscript received August 5, 2001.

This work was supported by the U.S. Department of Energy (DOE), Eergy Efficiency and Renewable Energy, as part of a DOE program to develop electric power technology, under Contract W-31-109-Eng-38.

B. Ma, R. E. Koritala, B. L. Fisher, R. A. Erck, S. E. Dorris, and U. Balachandran are with the Energy Technology Division, Argonne National Laboratory, Argonne, IL 60439 USA (corresponding author: Beihai Ma; phone: 630-252-9961; fax: 630-252-3604; e-mail: bma@anl.gov).

$\mathrm{M}$. Li is with the Energy Technology Division, Argonne National Laboratory as a postdoc fellow.

A. R. Markowitz is with the Energy Technology Division, Argonne National Laboratory as a co-op student. She is a student in the Materials Science Department, Northwestern University, Evanston, IL 60208 USA.

D. J. Miller is with the Materials Science Division, Argonne National Laboratory, Argonne, IL 60439 USA.
YBCO films on metallic substrates [4]. Several techniques, including ion-beam-assisted deposition (IBAD), rollingassisted biaxially textured substrates (RABiTS), and inclinedsubstrate deposition (ISD), have been developed in recent years [5-9]. When compared with IBAD and RABiTS, the ISD process produces textured films at high deposition rates $(20-100 \AA / \mathrm{sec})$ and is independent of the recrystallization properties of the metallic substrates [9].

We grew biaxially textured $\mathrm{MgO}$ thin films on mechanically polished Hastelloy C276 (HC) substrates by ISD with an electron beam (e-beam) evaporation system. Yttriastabilized zirconia (YSZ) buffer layers, ceria cap layers, and YBCO films were subsequently deposited on ISD-MgObuffered metallic substrates by pulsed laser deposition (PLD). Surface morphology was investigated by scanning electron microscopy (SEM), and surface roughness was measured by atomic force microscopy (AFM). The crystalline orientation of the films was studied by transmission electron microscopy (TEM). X-ray pole figures, as well as $\phi$ - and $\omega$-scans, were used to analyze texture. In this paper, we discuss the growth mechanism, microstructure, and dependence of biaxial alignment of ISD MgO thin films on film thickness; we also report the orientation relationships and superconducting properties of YBCO fabricated using ISD $\mathrm{MgO}$ architecture on polished $\mathrm{HC}$ substrates.

\section{EXPERIMENTAL PROCEDURE}

$\mathrm{HC}$ coupons $(\approx 5 \mathrm{~mm}$ wide and $10 \mathrm{~mm}$ long $)$ were mechanically polished to a mirror finish with $0.25-\mu \mathrm{m}$ diamond paste for use as substrates. A surface roughness of $\approx 3 \mathrm{~nm}$ was measured by AFM. A schematic illustration of the experimental setup is given in Fig. $1 . \mathrm{MgO}$ thin films were grown from an $\mathrm{MgO}$ source by e-beam evaporation. Fused lumps of $\mathrm{MgO}$ (Alfa Aesar, 99.95\% metals basis, 3-12 mm pieces) were used as the target material. The substrates were mounted on a tiltable sample stage above the e-beam evaporator. A substrate inclination angle $\alpha$ (substrate normal with respect to the evaporation direction) of $55^{\circ}$ was used in this study. Oxygen flow was introduced into the system during film deposition. The base pressure of the vacuum system was $1 \times 10^{-7}$ torr, which rose to $\approx 2 \times 10^{-5}$ torr during deposition. A quartz crystal monitor was mounted beside the sample stage to monitor and control the deposition rate. High 
deposition rates of $20-100 \AA / \mathrm{sec}$ were used, and the substrate temperature was maintained between room temperature and $50^{\circ} \mathrm{C}$ during deposition. After the deposition of ISD films, a thin dense layer of $\mathrm{MgO}$ was deposited at a zero-degree inclination angle at elevated temperature $\left(\approx 700^{\circ} \mathrm{C}\right)$. This layer of dense $\mathrm{MgO}$ film has the same crystalline texture as the ISD $\mathrm{MgO}$ film, and is thus referred to as a homo-epitaxial $\mathrm{MgO}$ layer.

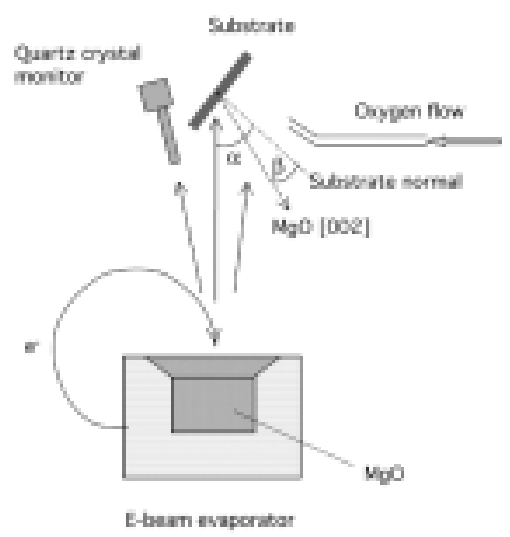

Fig. 1. Schematic illustration of experimental setup for ISD MgO.

YSZ, $\mathrm{CeO}_{2}$, and YBCO films were deposited by PLD using a Lambda Physik LPX 210i excimer laser, with a $\mathrm{Kr}-\mathrm{F}_{2}$ gas premixture as the lasing medium. Commercial targets (Superconductive Components, $99.999 \%$ pure), $45 \mathrm{~mm}$ in diameter and $6 \mathrm{~mm}$ thick, were used. Substrates were attached to a heatable sample stage with silver paste and heated to a high temperature $\left(700-800^{\circ} \mathrm{C}\right)$ during deposition. The size of the laser spot focused at the rotating target was $\approx 12 \mathrm{~mm}^{2}$, which produced an energy density of $\approx 2.0 \mathrm{~J} / \mathrm{cm}^{2}$. The distance between the target and the substrates was $\approx 7 \mathrm{~cm}$. The desired oxygen partial pressure was obtained by flowing ultra-highpurity oxygen through the chamber.

The superconducting critical transition temperature $\left(\mathrm{T}_{\mathrm{c}}\right)$ and $\mathrm{J}_{\mathrm{c}}$ were determined by the inductive method and confirmed by the transport method at $77 \mathrm{~K}$ in liquid nitrogen. Crystalline texture was measured by $\mathrm{X}$-ray diffraction pole figure analysis using $\mathrm{Cu}-\mathrm{K}_{\alpha}$ radiation. In-plane texture was characterized by the FWHM of $\phi$-scans for the $\mathrm{MgO}(002)$ reflection $(2 \theta=$ $42.9^{\circ}$ ), and out-of-plane texture was characterized by the FWHM of $\omega$-scans at the $\mathrm{MgO}$ [001] pole for the same reflection. SEM and AFM were utilized to study morphology and surface roughness.

\section{RESULTS AND DISCUSSION}

Plan-view SEM (Fig. 2a) shows a roof-tile structure for the ISD $\mathrm{MgO}$ film deposited at room temperature with $\alpha=55^{\circ}$. Columnar grains were observed on the cross-sectional fracture surface (Fig. 2b). The $\mathrm{MgO}$ grain size increased as the film grew up to a thickness of $\approx 0.5 \mu \mathrm{m}$; thickness of film; it then stabilized at a grain size of $\approx 0.2 \mu \mathrm{m}$ without a noticeable change in size when the film grew further. The root-mean- square (RMS) surface roughness was measured as $29 \mathrm{~nm}$ on an as-deposited ISD MgO film by tapping-mode AFM. E-beam evaporation of $\mathrm{MgO}$ at $700^{\circ} \mathrm{C}$ with a zero-degree inclination angle produced a smoother, dense homo-epitaxial layer (shown in Figs. 2c and 2d). RMS surface roughness was improved to $\approx 9 \mathrm{~nm}$ after the deposition of homo-epitaxial $\mathrm{MgO}$ films.
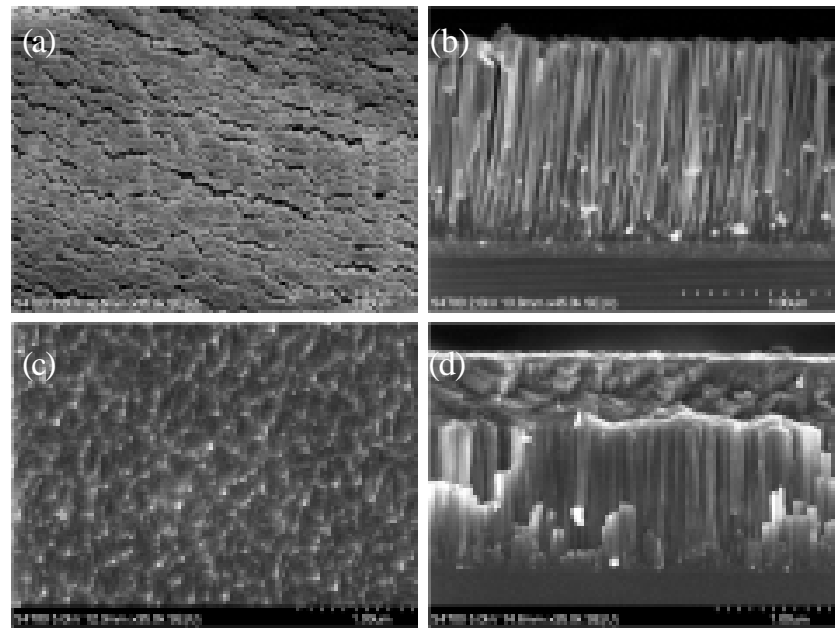

Fig. 2. (a) Plan view and (b) cross-sectional SEM images of ISD MgO film deposited at room temperature with $\alpha=55^{\circ}$; (c) Plan view and (d) crosssectional SEM images of $\mathrm{MgO}$ film after depositing additional layer of $\mathrm{MgO}$ e-beam evaporated at $700^{\circ} \mathrm{C}$ with $\alpha=0^{\circ}$.

Typical X-ray pole figures of an ISD $\mathrm{MgO}$ film deposited with an inclination angle of $55^{\circ}$ are shown in Fig. 3. Unlike the YSZ films prepared by inclined-substrate PLD [10], where the (001) planes are nearly parallel to the substrate surface, the [001] axis of the ISD MgO buffer layer is tilted away from the substrate normal. The asymmetric distribution of the pole peaks reveals that the $\mathrm{MgO}(001)$ planes have a tilt angle $\beta$ toward the deposition direction. These ISD MgO films exhibit good texture; distinct in-plane alignment can be seen by the well-defined poles for not only the [001] axis but also the [010] and [100] axes in Fig. 3. Out-of-plane alignment was characterized by $\omega$-scan; data were taken at the [001] pole.

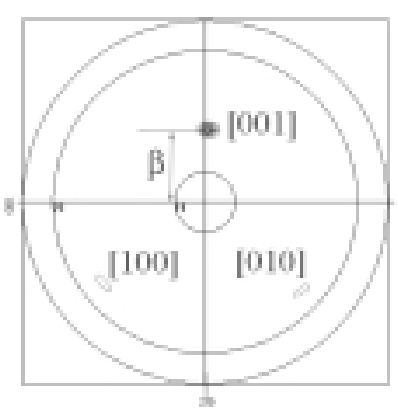

(a)

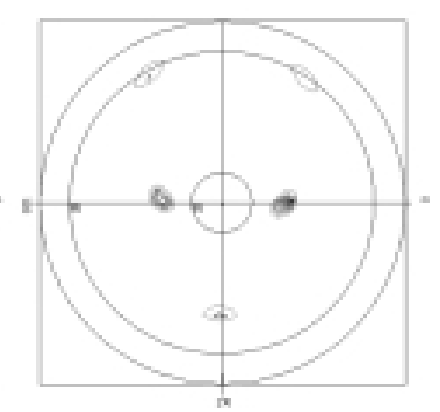

(b)
Fig. 3. (a) $\mathrm{MgO}(002)$ and (b) $\mathrm{MgO}$ (220) pole figures for an ISD $\mathrm{MgO}$ film deposited at room temperature with $\alpha=55^{\circ}$. 
The tilt angle, as determined from the chi angle value of the [001] reflection in the $\mathrm{MgO}$ (002) pole figure, was $\approx 32^{\circ}$. $\mathrm{TEM} /$ selected area diffraction on the ISD $\mathrm{MgO}$ films confirmed that the top surface of an $\mathrm{MgO}$ columnar grain was terminated with a (002) plane; and $\mathrm{MgO}[002]$ was $\approx 32^{\circ}$ with respect to the substrate normal $[11,12]$. Figure 4 shows the $\phi$ and $\omega$-scan patterns for $\mathrm{MgO}(002)$ after homoepitaxially growing a 0.5 - $\mu \mathrm{m}$-thick $\mathrm{MgO}$ layer on a $\approx 1.5 \mu \mathrm{m}$ ISD $\mathrm{MgO}$ film at elevated temperature. FWHMs of 9.2 and $5.4^{\circ}$ were observed in the $\mathrm{MgO}(002) \phi$-scan and $\omega$-scan, respectively.
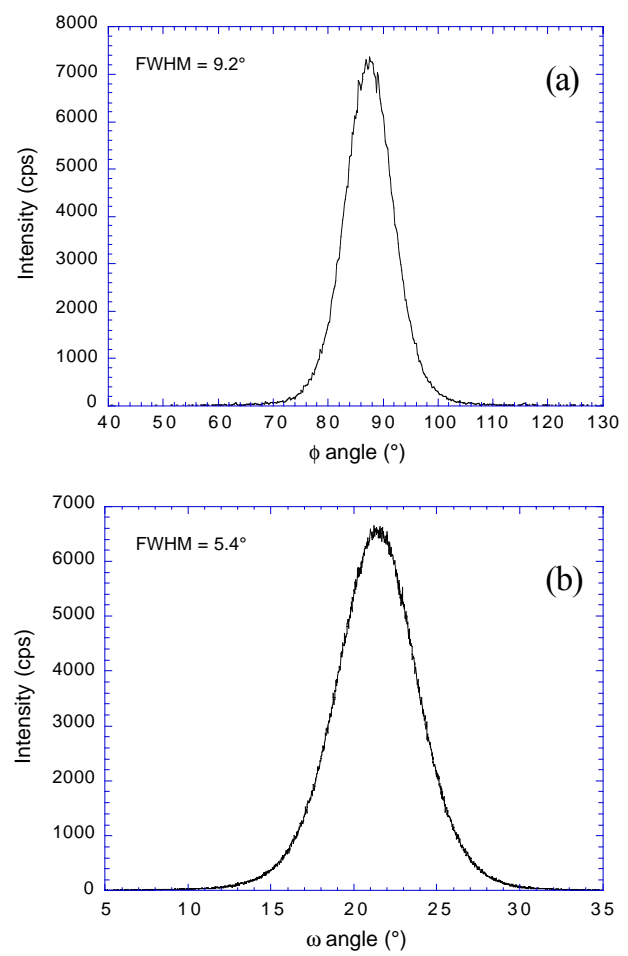

Fig. 4. $\mathrm{MgO}(002)$ (a) $\phi$-scan and (b) $\omega$-scan patterns after homoepitaxial growth of $0.5-\mu \mathrm{m}$-thick $\mathrm{MgO}$ layer on ISD $\mathrm{MgO}$ film at elevated temperature.

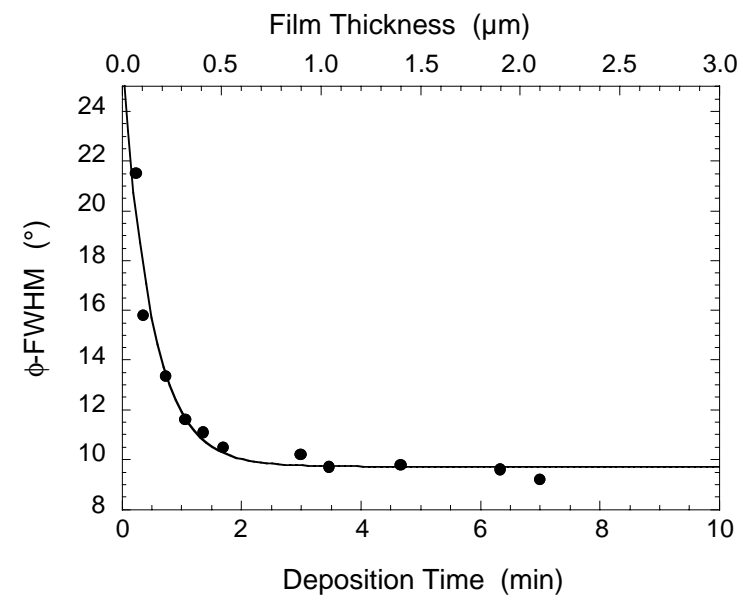

Fig. 5. Texture development in the ISD MgO film.
To study the thickness dependence of texture development in ISD $\mathrm{MgO}$ films, we first deposited ISD $\mathrm{MgO}$ films of various thicknesses followed by deposition of $\mathrm{a} \approx 0.5 \mu \mathrm{m}$ homoepitaxial $\mathrm{MgO}$ layer at $700^{\circ} \mathrm{C}$. Figure 5 shows the inplane texture as a function of ISD $\mathrm{MgO}$ layer thickness. In the first $0.5 \mu \mathrm{m}$, the $\phi$-scan FWHM decreases rapidly with increasing film thickness; it then stabilizes at $\approx 9^{\circ}$. Only $\approx 1.5$ $\min$ is required to fully develop the desired texture at a deposition rate of $50 \AA / \mathrm{sec}$. Furthermore, texture in the ISD $\mathrm{MgO}$ films has good tolerance to film thickness.

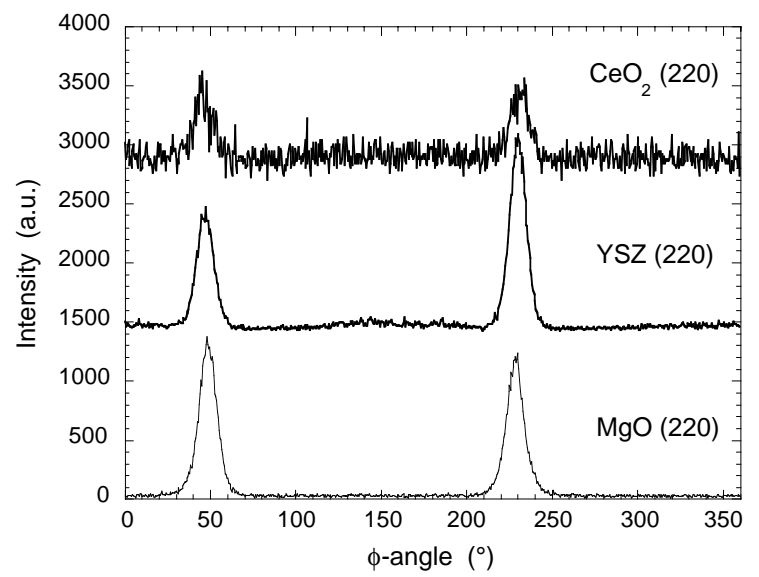

Fig. 6. (220) $\phi$-scans for $\mathrm{MgO}, \mathrm{YSZ}$, and $\mathrm{CeO}_{2}$ showing cube-on-cube epitaxial relationship.

YSZ and $\mathrm{CeO}_{2}$ films were epitaxially grown on top of the homoepitaxial $\mathrm{MgO}$ film by $\mathrm{PLD}$ at elevated temperatures $\left(700-800^{\circ} \mathrm{C}\right)$. Both $\mathrm{CeO}_{2}$ and $\mathrm{YSZ}$ layers have a cube-on-cube epitaxial relationship with the $\mathrm{MgO}$ film underneath. (220) $\phi$ scans plotted in Fig. 6 clearly showed a layer-by-layer epitaxy for $\mathrm{MgO}$, YSZ, and $\mathrm{CeO}_{2}$ films. Details of the epitaxial growth of YSZ and $\mathrm{CeO}_{2}$ on $\mathrm{MgO}$ films will be reported elsewhere [12].

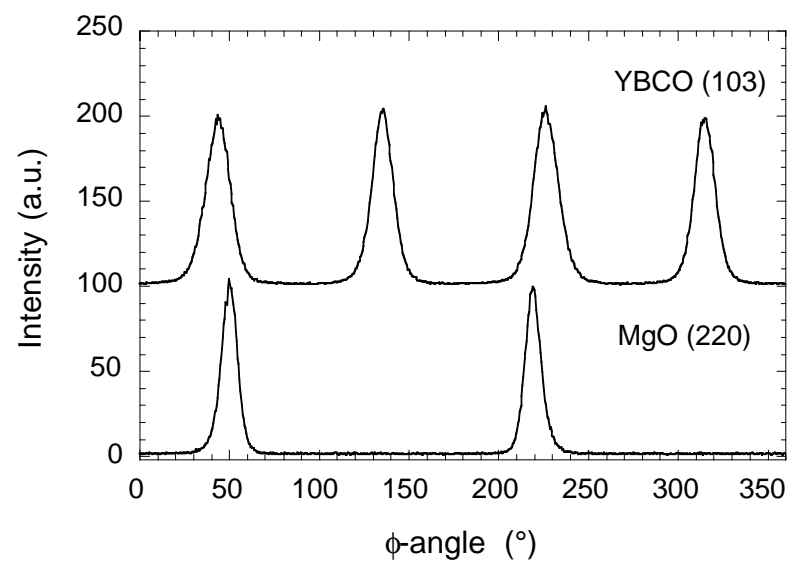

Fig. 7. $\phi$-scans for $\mathrm{MgO}(220)$ and $\mathrm{YBCO}$ (103). 
YBCO films deposited on YSZ- and $\mathrm{CeO}_{2}$-buffered ISD $\mathrm{MgO}$ substrates were biaxially textured. FWHMs of $12^{\circ}$ and $9^{\circ}$ were measured from YBCO (103) and $\mathrm{MgO}$ (220) $\phi$-scans, respectively, as shown in Fig. 7.

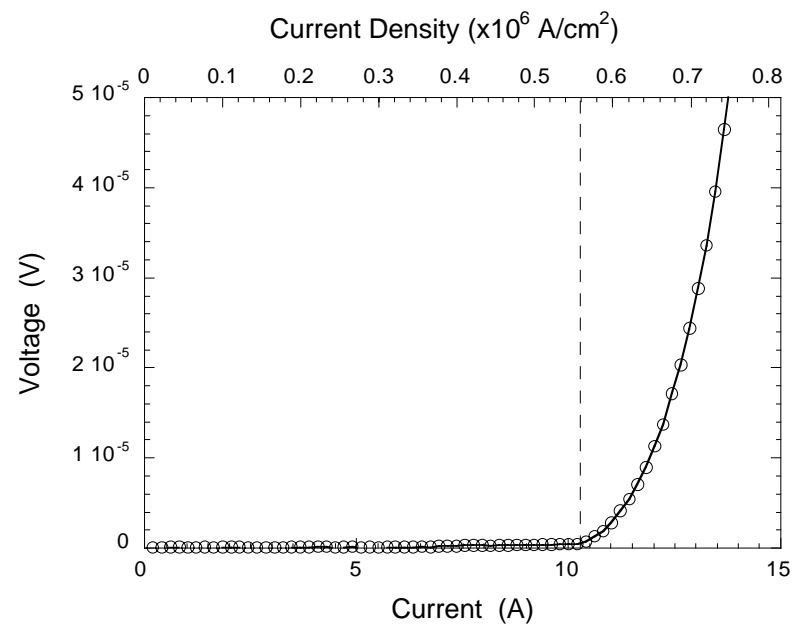

Fig. 8. Transport $\mathrm{J}_{\mathrm{c}}$ of $\mathrm{YBCO}$ on ISD $\mathrm{MgO}$ measured at $77 \mathrm{~K}$ in self-field

The YBCO c-axis was parallel to the substrate normal, as illustrated by four evenly distributed peaks on the YBCO (103) $\phi$-scan pattern. This revealed that the YBCO ab-plane was siting on a (112) plane parallel to the substrate surface. A unique orientation relationship, $\mathrm{YBCO}[100] / / \mathrm{MgO}[111]$ and YBCO $[010] / / \mathrm{MgO}[110]$, was observed between the YBCO and ISD $\mathrm{MgO}$ template films. YBCO coated conductors fabricated by ISD $\mathrm{MgO}$ architecture exhibited a sharp superconducting transition with $T_{c}=91 \mathrm{~K}$. As shown in Fig. 8, transport $\mathrm{J}_{\mathrm{c}}=5.5 \times 10^{5} \mathrm{~A} / \mathrm{cm}^{2}$ at $77 \mathrm{~K}$ in self-field was measured on a sample that was $0.46-\mu \mathrm{m}$ thick, $4-\mathrm{mm}$ wide, 1-cm long.

\section{CONCLUSIONS}

Biaxially textured $\mathrm{MgO}$ films were successfully grown by the ISD method, which is much more time efficient for fabrication of buffer layers than is the IBAD YSZ process. $\mathrm{MgO}$ films grown by the ISD process contained columnar grains whose surfaces were terminated by (002) planes. Planview SEM revealed a roof-tile structure. The surface roughness and biaxial texture of the ISD $\mathrm{MgO}$ thin films were significantly improved by deposition of an additional thin layer of $\mathrm{MgO}$ at elevated temperature. FWHMs of 9.2 and $5.4^{\circ}$ were observed in the $\mathrm{MgO}(002) \phi$-scan and $\omega$-scan, respectively. Texture in the ISD $\mathrm{MgO}$ films developed rapidly in the first $0.5-\mu \mathrm{m}$ of film growth, and then stabilized at $\mathrm{FWHM} \approx 9^{\circ}$ when the films grew thicker. $\mathrm{CeO}_{2}$ - and YSZbuffer layers were epitaxially grown on ISD $\mathrm{MgO}$ templates by PLD. YBCO films deposited on YSZ and $\mathrm{CeO}_{2}$ buffered ISD $\mathrm{MgO}$ substrates were biaxially textured with $12^{\circ} \mathrm{FWHM}$ measured on YBCO (103). A unique orientation relationship with $\mathrm{YBCO}[100] / / \mathrm{MgO}[111]$ and $\mathrm{YBCO}[010] / / \mathrm{MgO}[110]$ was observed between the YBCO films and ISD $\mathrm{MgO}$ template layers. YBCO coated conductors fabricated with ISD $\mathrm{MgO}$ architecture exhibited a sharp superconducting transition with $\mathrm{T}_{\mathrm{c}}=91 \mathrm{~K}$ and transport $\mathrm{J}_{\mathrm{c}}=5.5 \times 10^{5} \mathrm{~A} / \mathrm{cm}^{2}$ measured at $77 \mathrm{~K}$ in self-field.

\section{ACKNOWLEDGMENT}

SEM/TEM analysis was performed in the Electron Microscopy Center for Materials Research at Argonne National Laboratory. This work was supported by the U.S. Department of Energy (DOE), Energy Efficiency and Renewable Energy, as part of a DOE program to develop electric power technology, under Contract W-31-109-Eng-38.

\section{REFERENCES}

[1] D. K. Finnemore, K. E. Gray, M. P. Maley, D. O. Welch, D. K. Christen, and D. M. Kroeger, "Coated Conductor Development: An Assessment," Physica C, 320, 1-8 (1999).

[2] Y. Iijima and K. Matsumoto, "High-Temperature-Superconductor Coated Conductors: Technical Progress in Japan," Supercond. Sci. Technol., 13, 68-81 (2000)

[3] J. O. Willis, P. N. Arendt, S. R. Foltyn, Q. X. Jia, J. R. Groves, R. F. DePaula, P. C. Dowden, E. J. Peterson, T. G. Holesinger, J. Y. Coulter, M. Ma, M. P. Maley, and D. E. Peterson, "Advance in YBCO-Coated Conductor Technology," Physica C, 335, 73 (2000).

[4] D. Dimos, P. Chaudhari, and J. Mannhart, "Superconducting Transport Properties of Grain Boundaries in $\mathrm{YBa}_{2} \mathrm{Cu}_{3} \mathrm{O}_{7}$ Bicrystals," Phys. Rev. $B, 41,4038-4049$ (1990).

[5] Y. Iijima, M. Kimura, T. Saitoh, and K. Takeda, "Development of Y123-Coated Conductors by IBAD Process," Physica C, 335, 15 (2000)

[6] C. P. Wang, K. B. Do, M. R. Beasley, T. H. Geballe, and R. H. Hammond, "Deposition of In-plane Textured $\mathrm{MgO}$ on Amorphous $\mathrm{Si}_{3} \mathrm{~N}_{4}$ Substrate by Ion-Beam-Assisted Deposition and Comparisons with Ion-Beam-Assisted Deposited Yttria-Stabilized-Zirconia," Appl. Phys. Lett., 71, 2955-2958 (1997).

[7] A. Goyal, D. P. Norton, J. D. Budai, M. Paranthaman, E. D. Specht, D. M. Kroeger, D. K. Christen, Q. He, B. Saffian, F. A. List, D. F. Lee, P. M. Martin, C. E. Klabunde, E. Hardtfield, and V. K. Sikka, "High Critical Current Density Superconducting Tapes by Epitaxial Deposition of YBCO Films on Biaxially Textured Metals," Appl. Phys. Lett., 69, 1975 (1996).

[8] M. Bauer, R. Semerad, and H. Kinder, "YBCO Films on Metal Substrates with Biaxially Aligned MgO Buffer Layers," IEEE Trans. Appl. Supercond., 9, 1502 (1999).

[9] B. Ma, M. Li, Y. A. Jee, B. L. Fisher, and U. Balachandran, "Inclined Substrate Deposition of Biaxially Textured Magnesium Oxide Films for YBCO Coated Conductors," Physica C, 366, 270-276 (2002).

[10] K. Hasegawa, K. Fujino, H. Mukai, M. Konishi, K. Hayashi, K. Sato, S. Honjo, Y. Sato, H. Ishii, and Y. Iwata, "Biaxially Aligned YBCO Film Tapes Fabricated by All Pulsed Laser Deposition," Appl. Supercond., 4, 487-493 (1996).

[11] U. Balachandran, B. Ma, M. Li, B. L. Fisher, R. E. Koritala, R. Erck, and S. E. Dorris, "Fabrication by Inclined-Substrate Deposition of Biaxially Textured Buffer Layer for Coated Conductors," Proceedings of Materials Research Society Fall 2001 Meeting, Boston, Nov. 25-29, 2001.

[12] B. Ma, et al., "Pulsed Laser Deposition of Biaxially Textured YBCO Films on ISD MgO Buffered Metal Tapes," to be submitted to Supercond. Sci. Tech., (2002). 